This item was submitted to Loughborough's Research Repository by the author.

Items in Figshare are protected by copyright, with all rights reserved, unless otherwise indicated.

\title{
Exploitation, victimhood, and gendered performance in Rituparno Ghosh's Bariwali
}

PLEASE CITE THE PUBLISHED VERSION

http://dx.doi.org/10.1525/fq.2016.69.4.35

\section{PUBLISHER}

(C) University of California Press

\section{VERSION}

VoR (Version of Record)

\section{PUBLISHER STATEMENT}

This work is made available according to the conditions of the Creative Commons Attribution-NonCommercialNoDerivatives 4.0 International (CC BY-NC-ND 4.0) licence. Full details of this licence are available at: https://creativecommons.org/licenses/by-nc-nd/4.0/

\section{LICENCE}

CC BY-NC-ND 4.0

\section{REPOSITORY RECORD}

Dasgupta, Rohit, and Tanmayee Banerjee. 2016. "Exploitation, Victimhood, and Gendered Performance in Rituparno Ghosh's Bariwali”. figshare. https://hdl.handle.net/2134/22998. 


\title{
EXPLOITATION, VICTIMHOOD, AND GENDERED PERFORMANCE IN RITUPARNO GHOSH'S BARIWALI
}

\author{
Rohit K. Dasgupta and Tanmayee Banerjee
}

Rituparno Ghosh (1961-2013) was a filmmaker, lyricist, and writer who first emerged on the cultural scene in Bengal as a copywriter at Response, a Kolkata-based advertising firm in the eighties. He made a mark for himself in the world of commercials, winning several awards for his company before directing two documentaries for Doordarshan (India's national public television). He moved into narrative filmmaking with the critically acclaimed Hirer Angti (Diamond Ring, 1992) and the National Award-winning Unishe April (Igth April, I995). He is credited with changing the experience of cinema for the middle-class Bengali bhadrolok and thus opening a new chapter in the history of Indian cinema. ${ }^{\mathrm{I}}$

Ghosh arrived at a time when Bengali cinema was going through a dark phase. Satyajit Ray had passed away in I992, leaving a vacuum. Although filmmakers such as Mrinal Sen, Goutam Ghose, Aparna Sen, and Buddhadeb Dasgupta contributed significantly to his genre of "intellectual cinema," they did not have much command over the commercial market. The contrived plots, melodrama, and obligatory "fight" sequences of the action-packed Hindi cinema, so appealing to the masses, had barely anything intelligible to offer to those in search of a higher quality cinema. Increasingly, Bengali films became clones of earlier box-office hits. Filmmakers who were aware of the educated urban audience's abhorrence of the kind of films made by directors, such as Anjan Chowdhury, Swapan Saha, Sujit Guha, Anup Sengupta, and Haranath Chakraborty, relied instead on the rural or suburban audiences and the urban poor for box-office returns. The educated Bengali middle-class audience, which could not relate to the new populist films, turned away from movie theatres entirely. Bengali art-house cinema, as it is still called, scarcely found producers, and globally acclaimed directors suffered a major setback.

Film Quarterly, Vol. 69, Number 4, pp. 35-46, ISSN 0015-1386, electronic ISSN 1533-8630. (c) 2016 by The Regents of the University of California. All rights reserved. Please direct all requests for permission to photocopy or reproduce article content through the University of California Press's Reprints and Permissions web page, http://www. ucpress.edu/journals.php?p=reprints. DOI: 10.1525/FQ.2016.69.4.35.

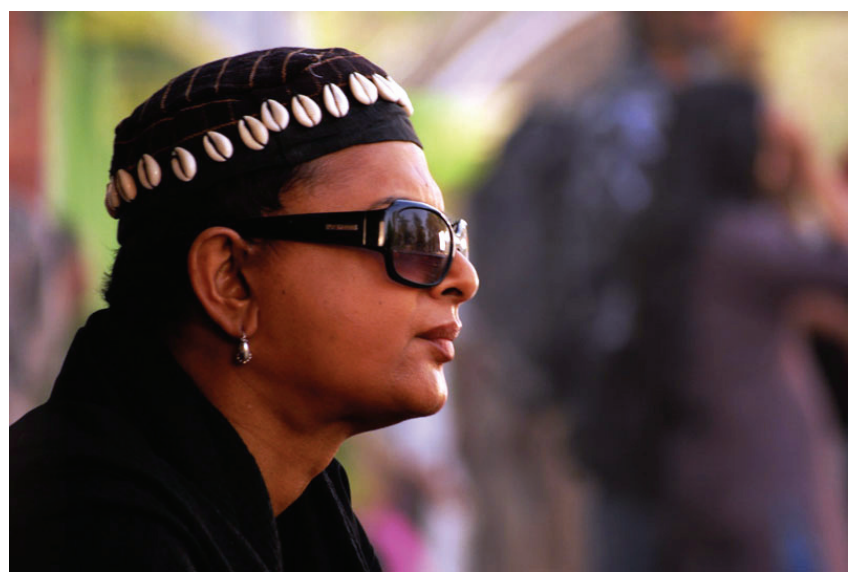

Rituparno Ghosh. @ Sangeeta Datta, 2013

Ghosh, clearly influenced by Ray and Sen, addressed the Bengali middle-class nostalgia for the past and made films that were distinctly "Bengali" yet transcended its parochialism. Ghosh's films were widely appreciated for their challenging narratives. His stories explored such transgressive social codes as incest in Utsab (Festival, I999), marital rape in Dahan (Crossfire, 1997), polyamory in Shubho Muharat (First Shot, 2003), the sexual desires of widows in Chokher Bali (A Passion Play, 2004), same-sex love in Chitrangada (Chitrangada: A Crowning Wish, 2012), and the moral hypocrisies of the new middle class in Dosar (Emotional Companion, 2006).

Often censured on the ground of his nonconformist gender and sexual orientation, Ghosh has constantly attempted to expose the sham progressiveness of a society that has more often than not been insensitive to human emotions and desires. ${ }^{2}$ Bariwali (The Lady of the House, 200o), one of his most important films, won two National Awards from the government of India. ${ }^{3}$ It clearly marked the beginnings of Ghosh's gender and sexual politics, which would finally culminate in Chitrangada, and was one of the first Bengali films to introduce a visibly queer character in Bengali cinema. Oddly, while his later films, including his queer trilogy, have received widespread attention from scholars in recent years, Bariwali has received almost none-even though its discourse of victimhood is narrated through the trope of gendered 
agency in the film, positioning hegemonic masculinity and heteropatriarchal privilege as markers of exploitation within India's gendered politics.

The central presence of Prasanna (Surya Chatterjee), the first identifiably queer character created by Ghosh, invites an interrogation into the boundaries of masculine performance and subjectivity and offers a contrast to the ways in which female agency is problematized against a masculine axis. The protagonist Banalata (Kiron Kher), positioned within both feudal space and bhadralok discourse, embodies the transition from tradition to modernity, from discretion to aggression, and from politeness to brazen appropriation in Ghosh's film.

\section{Situating Bariwali}

Bariwali is set in a suburb on the outskirts of Kolkata. Though it is one of Ghosh's first films (albeit continued in his later period dramas) to be set exclusively outside the urban space of the city, the characters extend Ghosh's ongoing preoccupation with mannered upper-/upper-middle-class people. Here Ghosh delves into the everydayness of a lackluster suburban aristocratic mansion occupied by the lineage's only surviving member, Banalata (Kiron Kher), a middle-aged spinster, who seems to be caught in a time warp. Banalata's life is basically idle, apart from small household chores, watching television, and scolding her domestic helps. Her only companions are an aging manservant, Prasanna, who has been serving the family since childhood, and an extroverted pert maid, Malati (Sudipta Chakraborty).

Into this mundane setting, diversion arrives in the form of a film production company, which wants to rent the house for a period drama. Banalata is secretly overwhelmed by the presence of these people, especially the beautiful actress Sudeshna (Rupa Ganguly) and the charismatic director Dipankar (Chiranjeet Chakraborty). Though aware that Dipankar has a wife back in the city and that he had been Sudeshna's lover in the past, Banalata finds herself charmed by this worldly man of a sort she has never encountered before. He even persuades her to play a small role in the film when the original actor in the role is suddenly taken ill. But once the film crew leaves, Banalata is forced back into her lonely existence. Her letters to the film director go unanswered, and a final betrayal comes in the form of a letter from the film crew announcing that her bit role in the film has been left out.

Bariwali originated as a story penned by Ghosh for a short fiction special issue of Sananda, a Bengali women's magazine, which he then adapted into the script and dialogue for the film. ${ }^{4}$ It is an important work for a number of reasons: it marks the debut of Kiron Kher, one of the most versatile actors in Bollywood and regional films, in Bengali cinema and for which she received the National Award for best actress. It is also one of the first Bengali films to introduce the queer figure, and it was Ghosh's third film to be recognized at India's National Awards.

For the urban educated Bengali, Rabindranath Tagore is an integral part of Bengali consciousness, and Ghosh was no exception. The influence of Tagore's writings and Satyajit Ray's adaptation and appropriation of Tagore into his cinema created an indelible impression on Ghosh's sense of aesthetics, particularly his filmmaking, and has been the subject of several discussions. ${ }^{5}$ Ghosh has borrowed bits and pieces from Bengali literary and cultural elements and made a mosaic out of them in Bariwali. Banalata, the protagonist, shares her name with the character created by Jibanananda Das, the most famous Bengali poet after Tagore, in his most celebrated romantic poem, "Banalata Sen," written in I934. Banalata embodies timeless beauty that bears traces of history and mythology, with whom the poet narrator wants to sit face to face at the end of his life's journey. Thus Banalata's existence remains confined only to the imagination of her admirer, the narrator in this case. He creates her and it is he who enjoys reminiscing about the beauty of his own creation.

Like Banalata's beauty, Charulata's literary accomplishments in Tagore's short story "Nashtanir" and Ray's film adaptation, Charulata (The Lonely Wife, 1964), wins the appreciation of her brother-in-law Amal, who is believed to have been instrumental in getting Charulata to make use of her literary talent. Charulata did not seek public recognition as a writer but appreciation from Amal of her intellectual prowess, which was on par with, if not superior to, his. In both cases the men were satisfied to believe that these women owed their achievements to them.

In addition to Charulata, Bariwali carries resonances of Ghare Baire (The Home and the World, I984), another film adaptation of Tagore's novel by Ray, particularly in Ray's discussion of patriarchy, desolation, exploitation, and in certain cases, the abandonment of women by the bhadralok. In Ghare Baire, Bimala the zamindar's wife meets a similar fate. Her husband makes every effort to impart Western education to her, to teach her Western customs and manners so that he can take pride in his wife and present her to his friends as his greatest achievement. However, everything falls apart when progressive Bimala, until then the creation of her husband Nikhil, begins to assert herself and defy her husband. Ray's successful adaptation of Tagore in a visual medium validated the writer's immortal significance in the cultural landscape of Bengal and India, whereas Ghosh's deployment of Tagore's novel within his own narrative reinforces the continuing contemporaneity of those issues and concerns. 


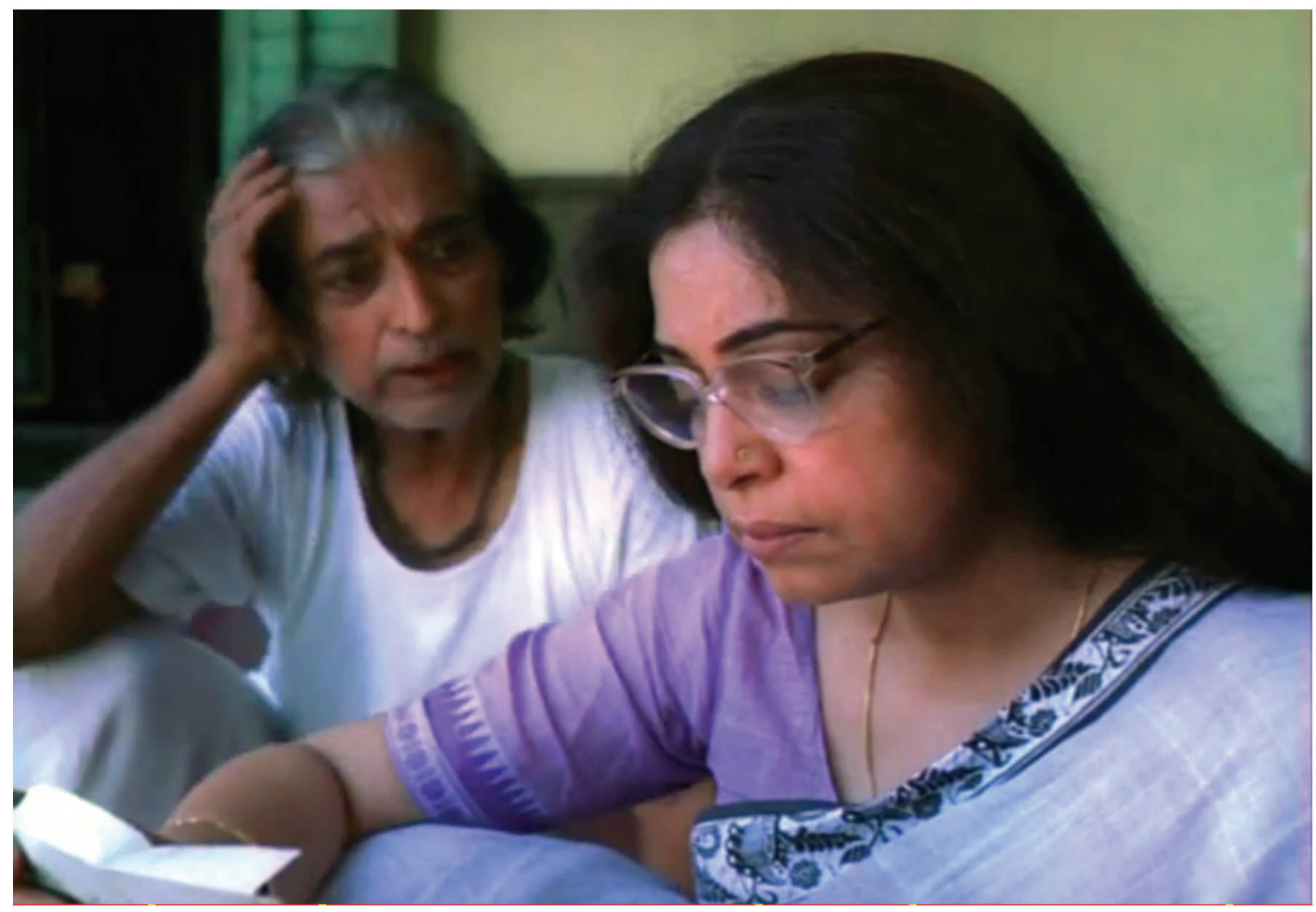

Banalata (Kher) and Prasanna (Chatterjee) talking to each other. @ Anupam Kher Company

Ghosh would film Tagore's novel Chokher Bali in 2003, but he was already paying attention to it in Bariwali, intelligently weaving its traces into the film's narrative in order to emphasize the continuity of its story of the exploitation of women in a heteropatriarchal society across two different timeframes. This continuity is validated through the plot of Bariwali and the relevance of its early twentieth-century text for women of the twenty-first century: for instance, when Banalata reads Tagore's Chokher Bali out loud to her maid Malati, she is interrupted by Malati's vehement criticism of Binodini, the young widow in the novel who yields to forbidden passions and boldly seduces a married man. Banalata's response, a compassionate understanding of Binodini's desolation, serves as Ghosh's first hint of the deep sense of frustration in the inner recesses of Banalata's mind.

\section{Class Divides}

One of Bariwali's most palpable and important aspects is the role of class as a strong influence on its characters. Banalata herself represents a fading aristocracy with a certain air of vulnerability. The first scene opens on the ornate yet lackluster entrance to Banalata's mansion. A tax-and-revenue settlement officer (a bhadralok in Bengali parlance) has come for an inspection; her servant Prasanna is showing him around and giving him necessary information about the family. Malati is about to serve tea while her lover Narayan coaxes her to accompany him to a movie; when he suddenly gropes and kisses her, the fancy bone-china cup and saucer reserved for special guests fall from her hand and break into pieces. Malati is absolutely nonchalant about the loss. Thus the narrative begins with a contemporary bhadralok, the tax settlement officer, trying to assess the value of a house that bears the remnants of Bengali tradition and conservatism; two lower-class people brazenly defying upper- and middle-class values and norms; and in between, someone with a "problematic" class and gender identity trying to mediate. Banalata is reduced to the status of a living remnant of an old feudal order, one that has been gradually eroded by social change and decadence. 
Historically the bhadralok class was a group of tax collectors and clerks who occupied some of the highest positions in the colonial administration. It coincides with the Bengal Renaissance, a time when the introduction of Western education led to the growth of a new class of intelligentsia. Indira Chowdhury argued that the stereotypes associated with the Bengali bhadralok were actually a way of justifying colonial rule. ${ }^{6}$ Unlike the bhadralok babu depicted in nineteenthcentury Kalighat paintings as effeminate gentleman leading scandalous lives and subservient to domineering wives, other indigenous conceptions of maleness were simultaneously being asserted through social discourses in which the Bengali bhadralok was seen to thrive on education, success, and social propriety. In creating this idealized hegemonic bhadralok masculinity, the bhadramahila (the gentlewoman) was cast as the repository of the family honor whose transgression had the power to dismantle this carefully constructed ideal of Bengali conservatism. Dipesh Chakrabarty has noted that the figure of the grihalakshmi (the chaste Hindu wife) symbolized the bhadralok's attempt to differentiate themselves from the colonizers, with the self-sacrificing Hindu wife positioned as an antithesis to the Eurocentric model of individualism. But Chakrabarty does not deny the violence concealed by this process of rewriting Indian womanhood through patriarchy. ${ }^{7}$ Tanika Sarkar reads this invention as an attempt by the bhadralok male to exert dominance within the private domestic sphere now that colonization had subordinated his position in the public sphere. ${ }^{8}$

The decadence of the feudal order is portrayed in Bariwali through the vulnerability and weakness of the old order in the face of changing circumstances. The film crew proceed to take advantage of Banalata in every way possible, from renting her house at a cost below its value to using her silver and furniture as props for their period film. Malati, despite her lower-class status, is represented as belonging to the new order with her street-smart understanding of the world around her. In fact, there is an unmistakeable resonance of E.M. Forster's classic masterpiece Howard's End in the characters of Banalata, Dipankar, and Malati, as Bariwali performs a similar emblematic dissection of the new class/ social relations in contemporary India.

\section{The Exploiter and the Exploited}

The film is about exploitation. . . The fact that the exploiter ... is a man, and the exploited is a woman, or rather two women, is merely incidental as I see it. The issue is not gender sensitive in that sense, but rather of universal vulnerability to the predatory instincts of the creative person. ${ }^{9}$
The theme of the oppressive man and the oppressed woman has been a recurring trope in many of Ghosh's films. In Unishe April Sarojini (Aparna Sen), a famous dancer, finds it difficult to reconcile the demands of her career and her home life, dominated by an egoistic husband who cannot put up with his wife's celebrity status. In Utsab (Festival, 2000) Parul (Mamata Shankar), the eldest daughter of an uppermiddle-class family, is trapped in an unhappy marriage, having failed to tie the knot with her cousin due to insurmountable family objections to the match. While most of Ghosh's films prior to Bariwali end with the emancipation of women from the forces that tie them down, or at least on a note of reconciliation, Bariwali ends in utter distress. Until the critique of aristocratic decadence and patriarchy in Antarmahal (2005), no other film by Ghosh ends on such a dismaying note as Bariwali. Its final shot, which focuses on the empty bed and the receding silhouette of the protagonist, transforms loneliness into a palpable object.

Banalata's vulnerability is subject not only to what Ghosh calls the "predatory instincts of the creative person," that is, Dipankar; her vulnerability also subjects her to other forms of exploitation which are revealed as the narrative unfurls. The film strikes at the core of middle-class values, especially those concerning sexuality and gender, through the lens of power and gender privilege. It also complicates gender performance and the discursive means through which dominance and power play out.

In Bariwali, Dipankar, Prasanna, and even Abhijeet (an actor in Dipankar's film, played by Abhishek Chatterjee) and Debashis (Dipankar's assistant, played by Shiboprasad Mukherjee) can be seen as different points on the axes of masculinity. One particular manifestation of masculinity, of course, is patriarchy, which in India as in the rest of the world shifted from its private nature, with women oppressed by husbands, fathers, and other male members of their family, to public patriarchy, where they are collectively subordinated by a society led by men.

In Bariwali, Banalata's first interaction with the world, at least metaphorically, is engendered by the arrival of the film unit. Her isolated life in the ghostly mansion is transformed overnight, as she is jolted into action by various requests, which the film unit members endearingly make to her. More consequently, she falls in love with Dipankar, the director, who overcomes her hesitations and coaxes her into renting the sprawling mansion for his shoot, while also overcoming the fortifications of conservatism that have guarded Banalata's sense of traditional morality for so long.

Smitten by Dipankar's educated, suave, and bhadraloki charm, both Banalata and Sudeshna allow him to exert his 


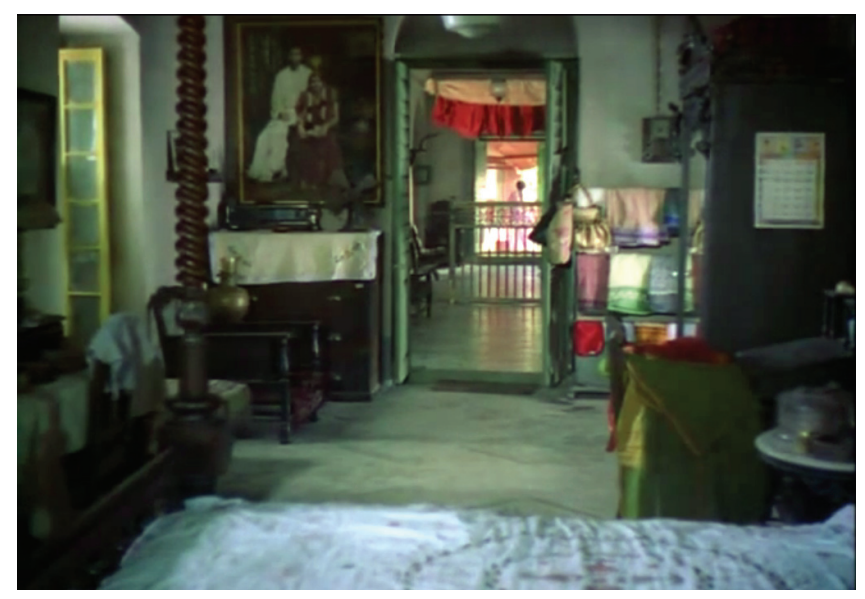

The final scene of Bariwali. (๑) Anupam Kher Company

agency upon them. Banalata offers her house, her personal belongings (even her father's portrait), and her special skills of lighting lamps and folding betel leaves. Breaking out of her puritan reservations, she also agrees to act in his film, allegedly to prevent his financial loss. Sudeshna cannot refuse Dipankar's offer either, and agrees to work in his film with nominal remuneration, even yielding completely to his strict taskmastership. In spite of his intentional aloofness in dealing with Sudeshna, Dipankar does not shirk from enlisting her assistance in coaxing her co-actor Abhijeet back to the shooting location when he leaves after a tiff with the assistant director.

It is important to recognize that Ghosh here is dealing with a very subtle form of exploitation. There is no physical or sexual abuse involved in the exploitation that victimizes Banalata and Sudeshna. They become victims as a result of Dipankar's shrewd manipulation of their emotional weaknesses. This subtlety also resonates in Ghosh's earlier work Unishe April, when in an emotionally charged scene Aditi (Debasree Ray) asks her mother (Aparna Sen), "Baba ki korto tomay?" (What did my dad do to you?), to which she answers, "Kichu korto na! Tumi ki mone koro mar dhor korlei kharap hoy?" (Nothing. Do you think physical abuse is the only expression of disregard?).

Ghosh has often brought to light such unseen violence/ exploitation meted out to women in his films. In a way, Ghosh is directly engaging with Sarkar's thesis of the neglected bhadramahila whose liberation and agency needed to be controlled, manipulated, and exploited to maintain a status quo at home, as if in compensation for a status quo that the colonial Bengali male had already lost to the colonizers in the public space.

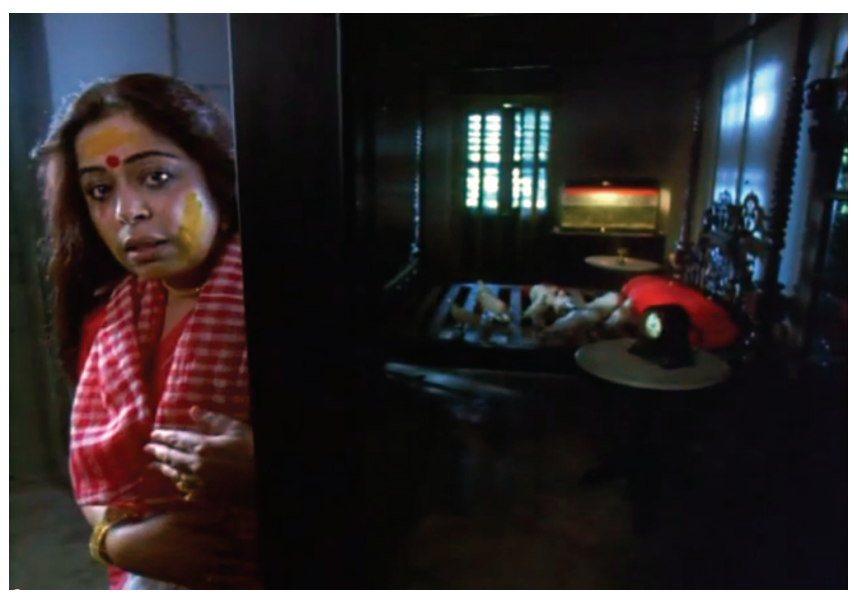

In Banalata's dream sequence, she imagines herself as a bride on her marriage day. (c) Anupam Kher Company

\section{Frail Masculinity and Queerness}

Prasanna is the first character from Banalata's household to whom the audience is introduced. He has been a companion in Banalata's childhood games; now he is the caretaker of the house, Banalata's personal assistant, her sole advisor on household matters, and her representative when it comes to dealing with outsiders. He is the only male character, perhaps the only person of any gender, with whom Banalata has shared her solitary existence.

Banalata does not seem to remember that Prasanna is a man. In a particular scene, with Prasanna sitting in front of her, Banalata reminds Malati that no man has ever dared to enter the inner chambers of the house. Prasanna fails to qualify as a male on the basis of the stereotypical parameters that are deployed in the appraisal of masculinity within a parochial socio-economic structure. If physical prowess, mechanical skill, and conscious nonchalance toward "womanly matters" are the conventional determinants of masculinity, Prasanna contradicts all. Prasanna's frailty and effeminacy offer a direct contrast with Dipankar's robust and overpowering masculine dispositions.

Prasanna is impressed by Dipankar's agility when he sees him leap over the railings of the terrace; he watches helplessly while Banalata tries to fix a blown fuse; furthermore, he indulges in typically "womanly" concerns by advising Banalata to switch the fan off before wearing her sari. Ghosh provokes a sense of discomfort with Prasanna from the very beginning. Banalata's loosening of her sari and baring her blouse in the presence of Prasanna unsettles the viewer. It becomes difficult to reconcile this particular act of Banalata with that of her conservatism that keeps her confined within the precincts of the house and does not even allow her to visit the ground floor of the house or meet strangers without 


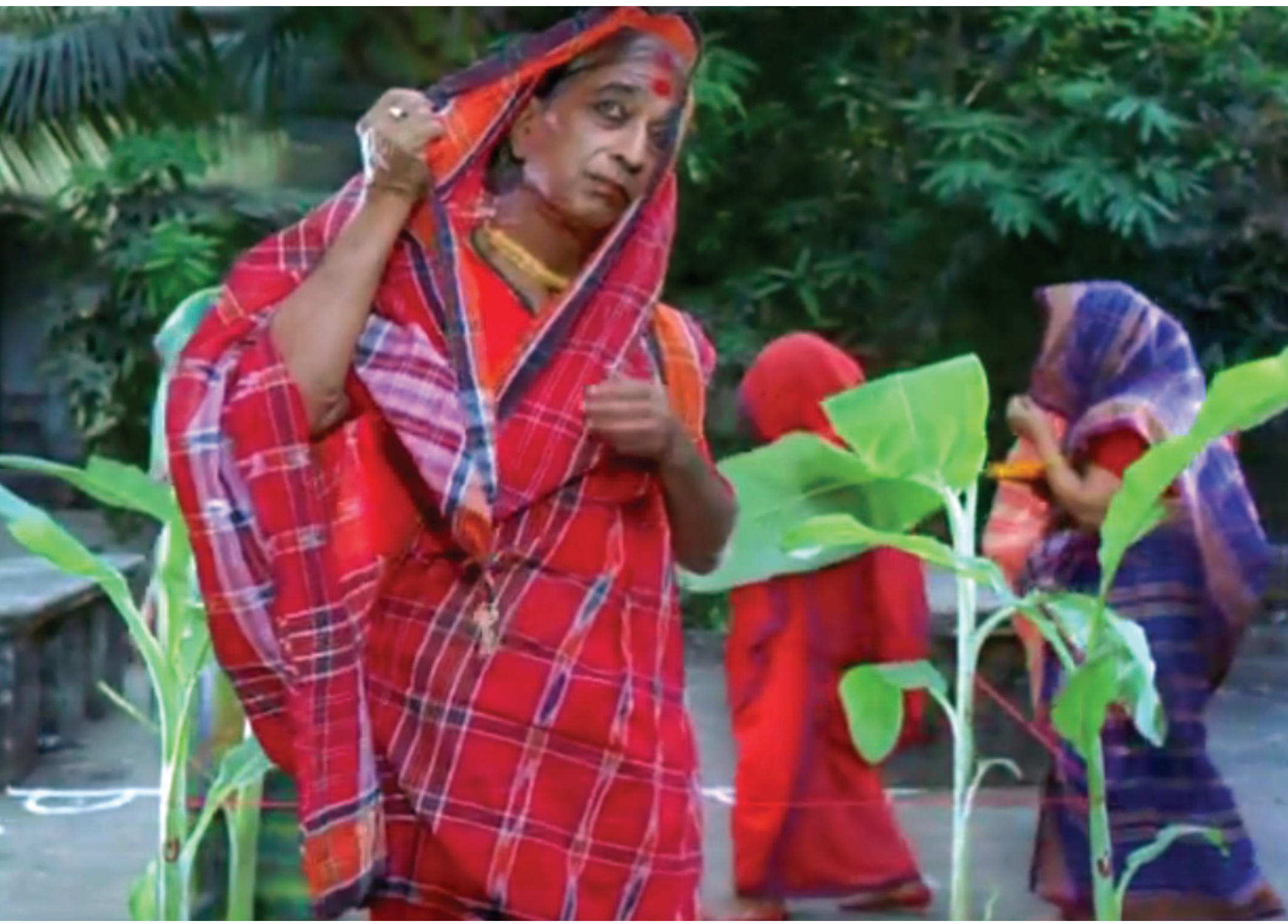

Prasanna queers wedding rituals in Banalata's dream. (c) Anupam Kher Company

a genuine cause. The piquing of the sense of discomfort among the viewers, for which the director had a specific purpose, reaches its height when Prasanna later appears in Banalata's dream, dressed in a sari and participating in stree achar (wedding rituals performed only by women). In an interview with Kaustav Bakshi, Ghosh agrees:

It's difficult not to miss Prasanna's queerness, so to speak. Banalata does not even treat him like a man. The relationship they share is not typical of a mistress of the house and her servant. Banalata shares everything with him, uninhibitedly; Prasanna has ready access to her bedroom; she does not even hesitate to change in his presence. Prasanna's queerness is best expressed in the first dream sequence, where Banalata dreams of him as one of the women, participating in stree-achar. ${ }^{\mathrm{IO}}$
For the viewer, the first reaction after seeing Prasanna in a sari with a conspicuous blotch of vermilion on his forehead and on the parting of his hair is that of surprise. His appearance is uncannily distressful, which intensifies the eeriness of the scene all the more when he mentions the death of the groom by snakebite. The sense of surprise (and possible discomfort for some viewers) with Prasanna has at its roots the inconceivability of the idea of a trans/queer individual in the popular Indian imaginary.

While Banalata does not acknowledge Prasanna's masculinity, Malati does not miss any opportunity for taunting Prasanna's "womanly" dispositions. Naturally bold by nature she ignores Prasanna outright. Moreover, she sees no difference between Prasanna and herself so far as their status in the house is concerned-they are both servants. Therefore, 
while Malati does not care to take his orders, her sarcastic remarks about Prasanna are targeted more toward the performance of the latter's gender identity - the basic masculine traits that he is expected to have, as opposed to his actual dispositions that confound the definiteness of the male/female binary.

Prasanna's cross-dressing/effeminate body is framed alongside Banalata's and Dipankar's bodies, and Ghosh often uses medium-length shots to underpin the "denaturalized" performance of Prasanna. In a telling scene, Prasanna can be seen walking onto the balcony drying his hair, with a group of men from the film crew in the background. Steve Derne in his work on culture, class, and gender in India understands gender to be a kind of act. In his ethnography with male filmgoers he argues that understanding of gender and culture is mediated through class, making a distinction between "locally oriented" middle classes that remain attached to traditional understanding of gender roles and position in society and a transnational Indian middle class embracing values and gender lifestyles depicted in Western media forms. ${ }^{\text {II }}$

Gender thus has a history that exists beyond the subject who enacts those conventions. Prasanna underscores and subverts dominant imaginations surrounding the male body and subjectivity. It is indeed ironic that Prasanna's "unmanliness" makes him an object of ridicule for Malati, who despite her inferior class status can challenge him, for he isn't "man" enough.

Ghosh has mentioned that the figure of Prasanna has belonged to a tolerant and benevolent feudal world, where he could live and inhabit female spaces without any problems. ${ }^{\text {I2 }}$ Through Prasanna, then, Ghosh was able to allude to the historical-social position of eunuchs and Third Sex beings in Indian queer history. ${ }^{13}$ Prasanna was guarding Banalata and the old mansion just like the eunuchs guarded female spaces and harems in ancient and medieval India. Prasanna is one of the first queer characters to be introduced in modern Bengali cinema and the first queer character created by Ghosh. Bariwali and Prasanna's character in particular can be traced to Ghosh's lifelong interest in narrating and critiquing the limits of the neoliberal identitarian discourse.

\section{Problematizing Agency}

In Ghosh's films, subjectivity and agency come from one's interactions with society and are shaped by the sociopolitical institutions within which one resides. Suffused with a questioning minoritarian agency, they bring an exploiter/ exploited binary into focus through the construction of character and narrative.
It is apt that Ghosh incorporates an intertextual reference to Chokher Bali's Binodini in Bariwali, given its tale of freedom and obstructed female agency. Sudeshna, who essays the role of Binodini in Dipankar's film, is a stark contrast to Banalata, who is limited by her social position within a suburban community. In the film, however, Ghosh uses Malati's character (especially her liaison with a hotheaded workingclass man, Narayan) to show how patriarchal exploitation works across intersectional lines.

The actions of Malati, Banalata's young maid, both disrupt and conform to patriarchal demands in interesting ways. Malati is in love with Narayan and is about to get married. She stands for the fulfillment of all of Banalata's unfulfilled dreams. Though Banalata does not miss any opportunity to exert her employer-like dominance over Malati, the latter is too stubborn to yield to or ignore the former's rebukes without a retort. Thus, Banalata's status as the employer fails to ensure that she is respected. Her vulnerability is recognized by Malati and there are several instances where they can be seen as equals. It is interesting to note that Malati draws her confidence essentially from the possibility of a married life, a normative proposition which forms a stark contrast to Banalata's single status with no hope of marital settlement.

However, Malati's handling of male agency and patriarchal exploitation is problematic. Initially she seems to ignore patriarchal control by defying Narayan's disapproval of her working and continues to work for Banalata. But the arrival of the film crew with male strangers changes those terms. She becomes the object upon which both the agencies of male domination and male gaze are exercised, as she ignores Narayan and enjoys Abhijeet's coquetry. In the end, however, Malati will acquiesce to Narayan's demand for his manly respectability by resigning from her job and refusing to live any longer in Banalata's house.

On another level, film director Dipankar's appearance and behavioral disposition conform to the idea of the Bengali bhadralok, as he embodies the abstract ideal of the desired man that Banalata had been nurturing throughout her life. Though Banalata does not unquestioningly accept the masculine order, as times goes by Dipankar encroaches on her domestic space. Subtly Dipankar tries to manipulate Banalata through her sexuality, twice offering his hand to her. Even though it might seem a casual gesture, in fact, a man offering his hand to a woman who is not related to him is a definite gesture of emotional (if not physical) intimacy within the conservatism to which Banalata subscribes. Similarly, Dipankar's polite words loaded with concern for Banalata also serve to manipulate her emotions. 


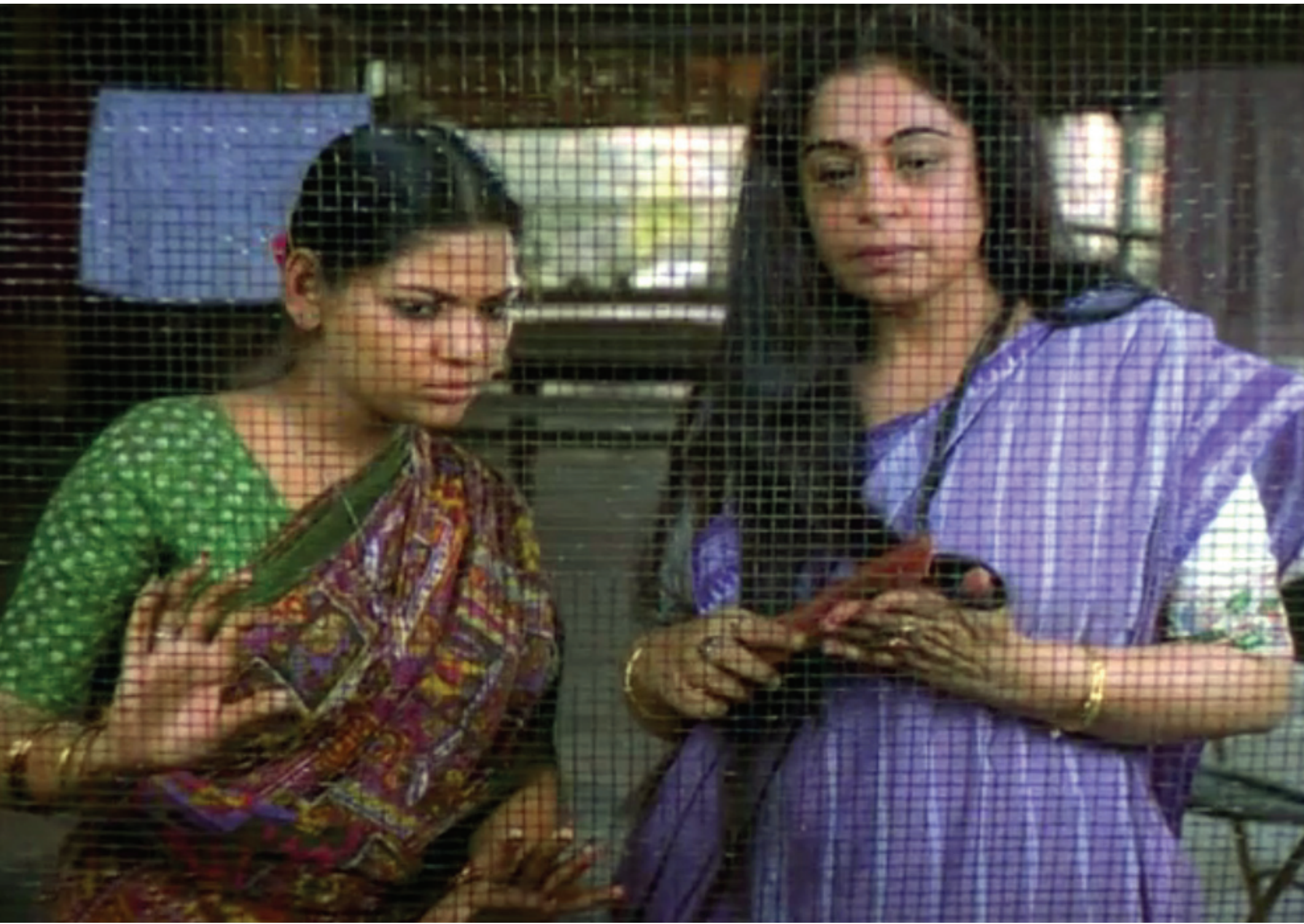

Malati (Chakraborty) and Banalata. (c) Anupam Kher Company

Dipankar's emotional drama with Banalata reaches its climax when he convinces her to play a small character part in his film. She is clad in a red and white sari, adorned with jewelry and vermilion on her forehead and a parting of her hair (the definite visual markers of a Hindu married woman) for the scene. This is thus a poignant cinematic expression, bringing into stark contrast the difference between the Banalata who is portrayed as a married woman in Dipankar's film and the Banalata, eponymous protagonist of Bariwali, who with a drab and dishevelled appearance languidly moves through her house, weighed down by desolation and repressed desires. It is impossible for viewers not to situate themselves in her position and try to imagine how things were, and how things could have been, for her.
Dipankar's opportunistic involvement and withdrawal is given cinematic expression through a wooden railing that is temporarily constructed to keep residents of the house and members of the film production team away from each other. Though the separating panel is entirely Dipankar's idea, throughout the film he crosses the boundary without permission and enters Banalata's room. This arrangement of temporary separation signifies Banalata and Dipankar's different attitudes toward the sense of boundary. For Banalata, the boundary gradually dissolves as she begins to misinterpret Dipankar's amiability as love. On the other hand, Dipankar makes use of the boundary to further his own interests. He crosses the boundary whenever Banalata's help is required, but eventually builds a more permanent "wall" of disregard, and 


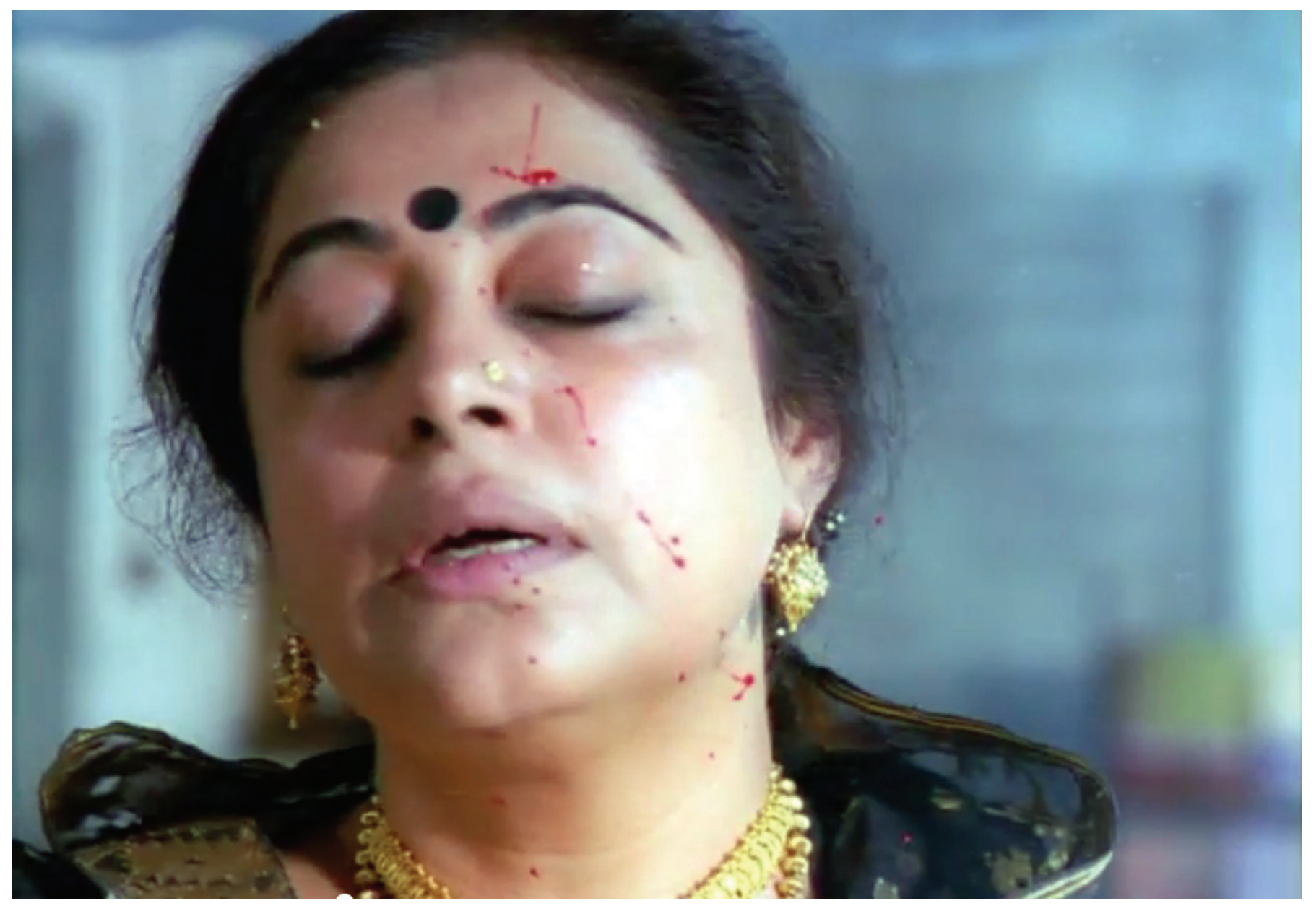

Banalata's dream sequence. ( ) Anupam Kher Company

stops communicating with Banalata altogether; he even cuts her scene out of the finished film without informing her, decisively casting her aside.

Ghosh uses a variety of striking visual tropes to register the complexity of Banalata's mind, especially her sexual repression, that is expressed through dream sequences. Triggered by her accidental witnessing of Malati and Narayan's physical intimacy, Banalata's repressed desires become manifested in her dreams. At night, sleep draws her into the mazes of her inner psyche and through her dreams a different reality finds expression: her longing for a man, a companion to ease her out of her drab and futile existence.

Banalata's long wait for a groom, as envisioned in her first dream, seems to come to an end with the arrival of Dipankar. There is a presence of a man in her second dream, too, who is none other than Dipankar. The apparently incoherent shots of white pigeons on clean white linen, of Dipankar painting the wall red and paint splashing on the floor, or a sequence of Banalata holding a virgin book with a brown cover and Dipankar splitting open the uncut pages of the book with a screwdriver, followed by spots of red spurting onto the face of Banalata as pigeons prowl on the red paint splashed on the floor-all are carefully composed visual metaphors for the idea of the loss of virginity that is cherished by Banalata in her dreams.

The female characters' deference to male agency reaches its climax in Banalata's dream of handing over her book to Dipankar as if ready to offer her untainted virginity to him. Ghosh's choice of a screwdriver for Dipankar to split the book's uncut pages recalls the powerful sexual metaphors created by Ray, both in Apur Sansar (The World of Apu, 1959) when Apu (Soumitra Chatterjee) holds his wife's hairpin as she wakes up and leaves the bed in the morning and in his Ghare Baire when Sandip (Soumitra Chatterjee) holds Bimala's lost hairpin, which he keeps as a memorabilia of their brief yet intimate encounter. Like the hairpin, Ghosh uses the screwdriver as a sexual metaphor; and in all cases, it is the man who is handed sexual agency, an agency that has been subtly yet penetratingly woven into the sociocultural discourses of Bengal. 
Bariwali's final dream sequence is even more explicit: Dipankar removes the coverlet under which Banalata is found lying in fancy lingerie. The coverlet, Banalata claims, has been embroidered through generations, thereby making it a signifier of the age-old tradition and conservatism that is being removed by Dipankar. Earlier, Banalata and Dipankar had passed Sudeshna's chic lingerie drying on a statue on the terrace, a scene that has a definite bearing on this dream in which the stylish innerwear becomes a direct signifier of desire. The fact that the underwear belongs to Sudeshna is significant: Banalata's jealousy of Sudeshna finds exquisite cinematic expression through the dream sequence. Thus, the presence of Dipankar in her dreams is always associated with sexual insinuations.

Ghosh has problematized issues of agency and freedom right from the opening scenes of the film: as a backdrop for the last title card and in a subsequent scene in which Prasanna lets the settlement officer into the temple. The film's opening on the house's antiquarian gateway is indicative not only of an old-fashioned architecture but also of the antiquated conservatism of its owner, Banalata. In the subsequent shot the perspective changes. The camera is placed inside the temple and captures the opening of the door and the entry of the two men into the temple. The surveyor enters the temple smoking a cigarette but on the insistence of Prasanna stamps it out on the floor. This scene communicates how the interior has no agency, no defense against its penetration by the outside world; nor is the temple able to preserve its sanctity from being sullied by the agents of the outside.

Banalata is the personification of this incapacitated interiority whose vulnerability will be exploited by an outsider, in this case Dipankar. In another intertextual reference to Ray's Ghare Baire, Ghosh shows that female emancipation (in this case Bimala's) occurs only when the interior has been left behind for the bahir [outsider]. Brinda Bose has argued that in the film, Bimala's passage toward sexual liberation is a return journey, a form of centripetal movement. ${ }^{14}$ In Bariwali too, Banalata's awakening and liberation occur when an "outsider" film crew take over her interior space; conversely, the return journey back to her cloistered existence after the exit of the film crew is a disciplining of her liberation and sexual transgression.

The character of Dipankar is primarily judged from the perspective of Banalata and Sudeshna, who was once involved in an affair with Dipankar and is still not able to break out of the attachment. Just as Dipankar's manly charm helps him gain access to Banalata's house and her heart, it also enabled his emotional exploitation of the actress Sudeshna.
A conversation between Sudeshna and her hairdresser (Sudeshna Roy) reveals that Dipankar knew Sudeshna could not refuse him when offered this film. He phoned Sudeshna to say, "I am making Chokher Bali and considering you for the role of Binodini. What about your available dates?" $\mathrm{He}$ is sure Sudeshna will not refuse him, and he is right, as seen in other scenes that show poignantly how smitten she still is with Dipankar. Ghosh subtly touches upon her desire when he shows her lightly place Dipankar's black shawl on her shoulder in one shot. The shawl, for her, is actually an extension of Dipankar with whom she desires a physical closeness.

Bariwali's intertextual references to Tagore's Chokher Bali are highly significant for its themes of unrequited love, sexual deprivation, and sexual jealousy. Banalata constantly plays an imaginary emotional tug-of-war with Sudeshna. Like Tagore's Binodini, Banalata too yearns for a companion and suffers from the same sexual deprivation, but unlike the former she is too conservative to break social taboos to gratify her desires. Just as Binodini's awakened sexual urge was intensified by her passive witnessing of Mahendra and Ashalata's overwhelmingly physical relation, so does Banalata's chancing upon the physical intimacy between Malati and Narayan stir up sexual desires that had been lying dormant in her subconscious mind. Also, her appreciation of Binodini's deprivation in Chokher Bali is indicative of her own pain. Finally, Sudeshna's casting as Binodini in Dipankar's Chokher Bali is highly significant, for like Binodini's relationship to the married couple in Chokher Bali, Sudeshna too is an outsider in Dipankar's married life.

It is worth mentioning that Ghosh does not entirely take away the possibility of Banalata's forging relationships with other people, nor are the entire film cast and crew presented as a homogenous group of oppressors. In fact the relationship that grows between Banalata and the assistant director Debashis is almost sibling-like, something that is permissible by society and therefore easy for her to handle. It is her sexual agency that is problematic in this regard. Sumita Chakravarty writes, "Female sexuality, on balance, is an aberration that is both exploiter and exploited." 15 While Malati uses her sexuality to her advantage, Banalata's female sexuality works against her. Bariwali critiques masculine patriarchal hegemony and brings the ostracized figure of the spinster to the center, thus problematizing gender inequality and dominance. The feminine dichotomy of the mother/ daughter, wife/widow is shaped by the male public sphere and is most notably apparent in Banalata's pains and joys foregrounded by her emotions in response to Dipankar.

Through Narayan, Dipankar, and Prasanna, Ghosh is able to project patriarchal hegemony and female victimization 


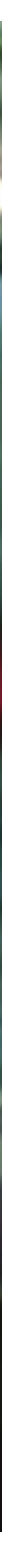

Sudeshna and Banalata filming a scene from Chokher Bali under Dipankar's direction. @ Anupam Kher Company

across class hierarchies and locations, metropolitan or suburban. Prasanna, who does not conform to the image of the "man," provides an interesting example of someone failing to live up to the expectations that heteropatriarchy makes of men thereby failing to find a "meaningful" life. Ghosh negotiates with the different registers of domination and exploitation through which heteropatriarchal power perpetuates itself. Banalata, Malati, and Prasanna are incidental victims who may well be unwittingly complicit in this heteropatriarchal discourse, which repeatedly establishes itself as inviolable, persevering despite muted or strident rebellions against it. Ghosh unravels two facets of this exploitation: seduction and force. Prasanna's alienation, on the other hand, occurs mainly because of his failure to imitate successfully enough the performative codes of conventional masculinity.

\section{Coda}

Bariwali is not just a film about the exploitation of a woman, as Ghosh himself claims - it is much more than that. By interweaving Bariwali with Tagore's Chokher Bali Ghosh situates his film within the discourse of exploitation in which the characters grow beyond their exploiter/exploited identity to become larger-than-life representations of social and cultural norms. Allowing the repressed desires hidden in the dark recesses of the human mind to see the light of day has been Ghosh's primary challenge throughout his life. He was less concerned with the fulfillment of those desires than with pulling back the veneer of social norms to expose the crude reality of exploitation lying underneath. Ghosh throws the conventional sense of propriety into question through the narrative of 
Bariwali, just as he did with his own life and work, informed always by his ideas of freedom, dynamics of personal relationships, politics of the home, identity, and sexuality. As strongly rooted in local Bengali culture as they are, his films remain remarkably global in their execution and ongoing appeal.

\section{Authors' Note}

The authors would like to thank Sangeeta Datta and Kaustav Bakshi for their sound advice. They would also like to thank the anonymous reviewers of Film Quarterly for feedback and comments. And special thanks to B. Ruby Rich, whose perseverance and editing made this article possible.

\section{Notes}

I. Sharmistha Gooptu explains that bhadralok indicates a certain social class among the Bengalis who, since the nineteenth century, have been the recipients of some kind of English/Western education. They were mainly engaged in the professions and services, and found in cinema a modern form, which could encapsulate the movement of their lives. This bhadralok middle class was the Bengali film industry's mainstay. See Sharmistha Gooptu, Bengali Cinema: An Other Nation (London: Routledge, 20ro). Also see Rohit K Dasgupta, Sangeeta Datta, and Kaustav Bakshi, "The World of Rituparno Ghosh: An Introduction," in Rituparno Ghosh: Cinema, Gender and Art, ed. S. Datta, K. Bakshi, and R.K. Dasgupta (London: Routledge, 2016), I-25.

2. Ghosh identified as an androgynous male and used his sartorial style to constantly challenge the rigid binaries imposed on gender through clothes. See Sumit Dey, "The Style of Being Rituparno Ghosh,” in Datta et al., Rituparno Ghosh: Cinema, Gender and Art, 83-I03. Also see Lipi Begum and Rohit K Dasgupta, "Contemporary South Asian Youth Cultures and the Fashion Landscape," International Journal of Fashion Studies 2, no. I (2015): I3I-45.

3. The National Film Awards is the most prominent film award ceremony in India. Established in I954 it is administered by the government of India. Every year, a national panel appointed by the government selects the winning entries in various categories, and the award ceremony is held in New Delhi, where the President of India presents the awards. Bariwali won the National Award for best actor (female) and best supporting actor (female). Ghosh himself won the Netpac Award for best filmmaker at the Berlin International Film Festival the same year.

4. Sananda is a respected woman's magazine that used to be edited by Aparna Sen.

5. See Dasgupta et al., "The World of Rituparno Ghosh: An Introduction."

6. Indira Chowdhury, Frail Hero and Virile History (New Delhi: Oxford University Press, I998).

7. See Dipesh Chakrabarty, "The Difference Deferral of a Colonial Modernity: Public Debates on Domesticity in British Bengal," in Tensions of Empire: Colonial Cultures in a Bourgeois World, ed. F. Cooper and A. Stoler (Berkeley: University of California Press, I997), 373-405.

8. See Tanika Sarkar, "Many Faces of Love: Country, Woman and God," in The Home and the World: A Critical Companion, ed. P.K. Datta (New Delhi: Permanent Black, 2003), 28.

9. Available in the DVD cover for Bariwali (Shraddha Records, 2000).

Io. See Kaustav Bakshi, "My City Can Neither Handle Me Nor Ignore Me: Rituparno Ghosh in Conversation with Kaustav Bakshi," Silhouette: A Discourse of Cinema ro, no. 3 (2013): 5.

I I. Steve Derne, Movies, Masculinity and Modernity: An Ethnography of Men's Filmgoing in India (Westport, CT: Greenwood Press, 2000).

I2. Personal conversation with the authors, 20 I I.

13. Also see Gayatri Reddy, With Respect to Sex: Negotiating Hijra Identity in South India (Chicago: University of Chicago Press, 2005) and Ruth Vanita and Saleem Kidwai, Same Sex Love in India: A Literary History (New Delhi: Penguin, 2008).

I4. Brinda Bose, "From Nashta Nir to Charulata: Ray's Creation of a Postcolonial Aura for Tagore Fiction," in Filming Fiction, ed. M. Asaddudin and A. Ghosh (New Delhi: Oxford Uniersity Press, 2012), I54-68.

15. Sumita Chakravarty, National Identity in Indian Popular Cinema (Austin: University of Texas Press, I993). 